2006-859: APPLYING FLIP/INVERTED CLASSROOM MODEL IN ELECTRICAL ENGINEERING TO ESTABLISH LIFE-LONG LEARNING

Larry Bland, John Brown University 


\title{
Applying Flip/Inverted Classroom Model in Electrical Engineering to Establish Life-long Learning
}

\begin{abstract}
Undergraduate engineering classrooms are experiencing changes as we strive to improve curriculum outcomes and develop students to meet the future challenges. Two important issues that face us are changing educational philosophies and techniques and the outcome requirements of ABET. Educational philosophies push us to consider a learner-centered approach over an instructor-centered teaching style. Research shows that students learn best when taught according to their particular learning style that may be dependent, collaborative, or independent. ABET has established the eleven program outcomes that all accredited programs must attain. Key to this paper is the professional skill of the "ability to engage in life-long learning."
\end{abstract}

The professor as the lecturer has dominated the typical engineering classroom, but the challenges above push us to active learning approaches where faculty are facilitators and students are much more involved in their own learning. The "flip" or inverted classroom model requires that material typically taught in lectures will be moved outside the classroom and additional active learning scenarios are integrated into class times for improved learning. This model transfers much learning responsibility to the students and develops necessary skills for life-long learning.

This paper looks at how this teaching model has been applied into undergraduate electrical engineering classes. Course modifications will be discussed, and qualitative and quantitative analysis of the courses provided for outcome analysis and continual course improvements. The results from this classroom model have been positive and will be discussed. However, there are also some cautions that will be discussed to improve dissemination of this model into additional learning environments.

\section{Introduction}

Undergraduate engineering classrooms are experiencing changes as we strive to improve curriculum outcomes and develop students to meet future challenges. Two important issues that face engineering educators are changing educational philosophies and techniques and the outcome requirements of ABET. Active learning educational philosophies push us to consider a learner-centered approach over an instructor-centered teaching style. In addition to changing our teaching style, we have become aware of the different learning styles of our students. Research shows that students learn best when taught according to their particular learning style that may be dependent, collaborative, or independent. ${ }^{1}$ Course design must strive to integrate these elements of teaching and learning for all styles. Also, ABET has established the eleven program outcomes that all accredited engineering programs must demonstrate. Key to this paper is a learning environment that emphasizes the professional skill of "ability to engage in life-long learning." 2 
To effectively integrate these two issues into a teaching model, we must understand the attributes of life-long learning, design a teaching approach that incorporates these attributes without reducing the educational content, assess the student development in this new environment and make adjustments as problems development.

\section{Life-long Learning}

The ABET criteria does not define the various attributes of "ability to engage in lifelong learning." The various institutions create their own definitions. By virtue of these differences, each institution also creates its own assessment process and tools. From the basic concept of life-long learning, we will not measure this outcome while the student is at our institutions. Life-long learning can only be demonstrated over a thirty-plus year career. We must look at career learning interventions, understand which interventions have the greatest impact on life-long learning, and implement those attributes that can be implemented well in a classroom.

Education and learning take place along a four-part continuum with formal, non-formal, informal and experiential interventions. Table 1 shows many of the characteristics of these interventions.

\begin{tabular}{|c|c|c|c|c|}
\hline & Formal & Non-Formal & Informal & Experiential \\
\hline Structure & High & $\begin{array}{l}\text { Medium to } \\
\text { Low }\end{array}$ & Minimum to No & No \\
\hline Maintenance & High & Minimal & Almost None & None \\
\hline Format & Lecture/class & Small Group & One-on-One & One \\
\hline Control & Professor & Speaker & Relationship & Student \\
\hline $\begin{array}{c}\text { Student Control } \\
\text { of Content }\end{array}$ & $\begin{array}{l}\text { Limited to } \\
\text { None }\end{array}$ & $\begin{array}{l}\text { Limited to } \\
\text { None }\end{array}$ & Increase & High \\
\hline Time & $\begin{array}{l}\text { Set by Degree } \\
\text { Requirements }\end{array}$ & $\begin{array}{l}\text { Days or } \\
\text { Weeks }\end{array}$ & $\begin{array}{c}\text { Short } \\
\text { Encounters } \\
\text { Over Long } \\
\text { Time }\end{array}$ & $\begin{array}{l}\text { Dependent } \\
\text { on Task }\end{array}$ \\
\hline Reward & Grades/Degree & Certificate & $\begin{array}{c}\text { Dinner/ } \\
\text { Promotion }\end{array}$ & $\begin{array}{l}\text { None/Job } \\
\text { Completion }\end{array}$ \\
\hline
\end{tabular}

Table 1. Educational interventions on a continuum.

Our universities exist in the realm of formal education with very intentional learning, grades, high structure, limited student control of content, and the outcome of a degree. New philosophies move the format from the lecture to more active learning techniques, but the classical lecture continues for many. Non-formal interventions are characterized by seminars: much less structure, still intentional learning, no grades, limited student control of content, and certificates. Informal interventions are characterized in the mentoring or peer team activities: one-on-one relationship encounters, minimal to no structure, increased student control, learning by doing, and more intrinsic reward of accomplishment. Experiential learning is our least structured form of educational intervention and is sometimes termed as incidental or consequential in nature. It is characterized by: the highest student initiative expressed in total 
control of the learning content, process, length, and depth; lasts only long enough to complete a given task or solve a specific problem; no perceived resultant reward or only the intrinsic satisfaction of knowing that a task is completed. The experiential process of education and learning may not be specifically recognized since it takes place as a part of other activities that are not normally associated with learning. Research has shown that informal and experiential learning are dominant as an individual proceeds through a career. ${ }^{3}$

By looking deeper at these interventions and their characteristics we recognize some key attributes of life-long learning:

- Strong student control of their own learning - There is not a formal classroom and the professor and lectures are not typically available to the career individual. Companies create assignments, expect results and do not anticipate some form of continued formal education to reach a solution. The working individual must already have requisite knowledge for a situation or obtain that knowledge from a source that would accommodate short-term encounters and quick information exchange. Giving the student more control in our classrooms couples with active learning paradigms.

- Learning is motivated by immediate, real-world needs - In the university setting, students are establishing a foundational knowledge base that will be applied to a future career situation. Urgency is created by homework or paper and test deadlines and typically bounded by the current subject matter or previously learned information. Within the work environment, urgency and subject matter are bounded by the problem at hand, competitive needs or external pressures to perform both technically and in a timely manner.

- Dominant career learning interventions are informal or experiential - This characteristic motivates the individual to learn independently, obtain information from a more senior individual or obtain knowledge in collaboration with peers or team members.

- Individuals learn at different paces - Learning is not necessarily sequential and linear in nature. For the career learner, their learning is driven by the problem at hand. Some learning will be established prior to beginning a design. Some will be learned through trial and error as implementation and testing proceed toward a completed product. Various team members will proceed with their learning at different rates. Many elements of this trait are obvious within the university environment. However, we have one strong overriding constraint. Semesters or quarters begin and end on a specific timetable. We will maintain that timing regardless of the learning situation. Grades indicate the level of learning within that time restriction. Within the career environment, learning does not end until the solution is found and the customer is satisfied. Grades will not be given. The closest similarity may be continued employment or a follow-on contract due to good performance. Learning itself is not measured, but design results and customer satisfaction are. 
An understanding of these attributes of life-long learning was key to course redesign. We identified ways to incorporate the first three life-long learning elements. The first goal was to significantly reduce or eliminate lectures. The working world does not provide lecture solutions for the issues that they are addressing. Seminars may address some small sub-element of instruction, but even then the career individual would be in control of deciding to learn on their own or attending the seminar that assists in their learning. With the elimination of the formal lecture model, we incorporated tasks that were intended to motivate independent or team related learning activities. This was targeted to replicate career-learning by informal or experiential interventions.

By creating an environment that encouraged team or individual learning, we were also addressing the issue of student control. It was recognized that within the original interventions of formal learning, learning was strongly controlled by the instructor. We are not leaving the formal learning environment, but we want to incorporate elements of the informal and experiential learning interventions. We do not reduce any control of course content or sequencing. We did want the student to develop some control of their learning. This required us to release some of our control of the situation while demanding more of the student. If we did not lecture on the material, but demanded results that required usage of the information, then the student had to take control of their learning in order to perform the tasks that were required of them.

Finally, it was recognized that urgency of real-world needs could be quickly addressed by proper assignment of homework, presentations, designs, and tests. The career world creates structure to task performance through project schedules and contractual requirements and milestones. The learning interventions within those task structures occur in a less structured process. For our students, we were not willing to give up on some of our structure. For example, in our Electrical Systems course, Ohm's Law must be understood prior to Kirchhoff's Laws, then Thevenin and Norton equivalent circuits and building to first, second and higher order circuit relationships. But the syllabus was treated like a project schedule with some class deliverables due for each time that we would meet. Formal rubrics were created for presentations, designs, and papers that came closer to simulating contractual requirements. We did not relinquish this area of our formal intervention, but used it to create a sense of urgency and to motivate the learning process.

\section{Course Design}

The requirement to remove or reduce the lecture component of our teaching environment was directly compatible with changes in teaching philosophy that have shifted focus from an instructor to an active learner model. We chose the flip or inverted classroom model as our basic structure for course design. These models were developed by moving things that were typically in the classroom, e.g. the lecture, to an outside environment, and adding more active learning elements into the course meeting times. ${ }^{4,5}$ These models have often been coupled with video streaming and lectures that were placed on-line with required viewing prior to classroom activities. In our case, we did not implement the lecture since this is not 
compatible with life-long learning models. Problem and design assignments were utilized to more appropriately model the working environment.

We utilized Dee Fink's ${ }^{5}$ taxonomy of significant (active) learning with major categories of: foundational knowledge, application, integration, human dimension, caring, and learning how to learn. A key element of life-long learning is to know how to learn. As our courses were designed we started with the student having to pursue the foundational knowledge. First, courses in both the sophomore and junior level classes were chosen. Specifically, this format change has been applied to Digital Systems and Electrical Systems I. Next, out-of-class assignments were established to create structure and steadily increase knowledge and complexity throughout the semester. Student participation in the pre-class activities is paramount to success of the learning scheme. Therefore, there were graded assignments for most class periods with measurable impact on their final grade.

These pre-class activities resulted in over 30 graded assignments. In order to handle the increased grading load, the students graded their own assignments at the beginning of each class. This provided for rapid feedback of performance to the students and developed areas for clarification and reinforcement during the class periods. There is some concern that the students will not grade their work honestly. During the grading of the papers there has to be careful monitoring of classroom activities to make sure that answers are not being copied and perfect grades recorded. There also needs to be random auditing of all inputs to look for breakdowns in integrity.

The in-class activities are aimed at application and integration. Clarification and expansion of course concepts were addressed with additional problems, case studies, physical examples, and integration of concepts into real world situations. In rare instances, there was sufficient confusion to warrant a mini-lecture. Efforts were made to model this mini-lecture intervention in a manner similar to mentoring or team interaction (informal learning). The student requesting information would have to clearly identify their areas of confusion. The intent of the instructor was not to simply provide the answer, but lead the student to information sources for problem resolution. Sometimes the student was given the chalk and had to outline his understandings, or lack thereof, at the front of the class. Using the rest of the class as a team, there was interaction to understand the areas of confusion and develop the necessary concepts for problem resolution.

To reinforce "learning how to learn," the students were encouraged to read text material, use outside references to assist in answering questions, and develop study groups for collaborative learning. Collaborative study groups formed very naturally. It was soon quite apparent which students were involved in each group and that group dynamics had developed well for collaborative learning.

Additional course assessment and learning came through a series of exams and application design projects. These areas were not modified from the traditional formal education measurement processes. It was anticipated that learning that resulted from this process area came through collaborative study activities that proceeded the specific exam or 
project. Study guides were not provided, as this would not properly replicate a career environment.

Key changes to the classroom were: lectures in their traditional format were eliminated, in-class time was spent clarifying understandings, resolving questions, expanding on both theory and application for a deeper understanding of the concepts, looking at real world applications, and providing design practice to the students.

\section{Course Evaluations}

Both qualitative and quantitative evaluations were used to determine if course changes were having their desired impact on student outcomes. The qualitative observations were obtained both in and out of class. The quantitative assessments came from course evaluations and a survey of student perceptions.

When the course structure was initially presented as a part of the syllabus, the reaction from the students was very neutral. There was a "wait and see" attitude toward the new process. Early course response was very positive. The students quickly created their own study groups, participated at almost $100 \%$ rate on out-of-class homework completion, and considered the class to be quite simple. Some students even commented that: "This class is easy. Can we move at a faster pace?" However, as the semester progressed and the material became steadily more complex, dynamics changed.

Due to our facility layout, a student study area has developed outside of my office door. Groups from these classes have naturally used this area as their physical point of learning and enabled me to observe their interactions. As complexity increases, a certain amount of frustration is observed. The material is harder to grasp, additional study is required and questions increase. As students are discussing the problems and potential methods of solution, a very common statement heard was "Why?" It is interesting to observe the students teaching each other and challenging the various approaches that arise. Discussions often reveal more than one way to solve a problem. The interchanges begin with the theory that they obtain from the text and exchange of various ideas of how to apply that theory for problem solution. Key to their learning is the collaborative process that will carry them through life-long learning. Many of the students also take on the role of instructor or mentor, which greatly enhances their own learning.

Due to the proximity to my office, it is common to have a student enter to ask questions about problems. In order to maintain my learning intervention goals, it is very important to not revert to the role of a lecturer. If the student is totally lost, information sources were identified where the concept is explained and then the student was sent to determine how the concept might be applied to their particular problem. Most of the time, a series of guiding questions will stimulate a particular direction of thought, or a question can point out a flaw in the current thought process and stimulate change. Within this learning process, the professor works as a helmsman or navigator that keeps things on course, but leaving it up to the students to propel things from one point to another. 
During the first semester that this course format was used, there developed a particularly high level of frustration during the final month of the course. Students were first introduced to forced and natural responses of first and second order systems, and they did not grasp the concepts and theory. At the beginning of one class there was a pointed outburst from a group of students, "Are you ever going to lecture prior to assigning problems? We need the lecture because we are lost." This was a rather difficult class period. As the instructor, there was the immediate desire to revert to lecture. It was the easiest way to appease the students and proceed. But it was not the way to reinforce the learning interventions that they would need later in their career. The in-class discussion looked at additional problem solving and introduced applications that would illustrate the theory and its practical application.

From this observation, the course had to be evaluated and re-designed. The original design always added new concepts into pre-class activities. There was never an explicit review or reinforcement of a concept except to the extent that it was necessary and foundational to the next stage of theory development. From this experience, the course was modified to incorporate some specific review problems at strategic points where frustration and theory reinforcement was needed for smoother student progression. During subsequent courses, this review helped to develop student confidence and reduce frustrations.

Two different quantitative surveys were administered to determine the student's perceptions of the course. The first survey was a series of attitudinal questions where each student was asked to indicate their extent of agreement or disagreement with the statements on a five-point Likert-type scale ( $5=$ Strongly Agree). The strongest indicators from a bank of 25 questions were:

- "Class discussions clarify areas of misunderstanding." (4.1)

- “Class examples effectively help me to understand the material."(4.2)

- "In-class time is spent more on application/problem solving rather than presenting facts." (4.2)

- "Class discussion requires critical thinking." (4.1)

- "Compared to other classes, I am more responsible for my own learning." (4.1)

- "I am learning skills that will help me be a life-long learner." (4.1)

- "Homework and class discussion directly relate to each other." (4.6)

The students were also asked to indicate whether they saw themselves as dependent, independent, or collaborative learners. The results indicate that $62 \%$ saw themselves as collaborative, $31 \%$ as independent, and $7 \%$ as dependent. 
Correlation analysis was performed on the data. For the statement: "I was a member of a peer study group outside of class," there was some strong, but rather expected correlation to statements of:

"I feel that I learn from my fellow students through the preparation required prior to class." (0.84 correlation)

"This class encourages me to spend more time collaborating with other students than I typically do in other classes." $(0.85)$

"I feel that I learn from my fellow students through the class discussion activities."

An interesting, but unexpected correlation was to the statement: "I learn best from lecture." (0.82) This result caused me to evaluate this small group of dependent learning individuals closer. They were not being given the lecture that they stated as preferred. They will not get that lecture in life-long learning environments. Therefore, there was a strong indication that their adapted learning intervention is collaborative as they sought out others to interface with and learn from.

The strongest levels of negative correlation were also indicated to the statement of: "I learn best from lecture."

"I like this class and would want it in additional classes." $(-0.83)^{*}$

"I find this class format to provide a deeper level of learning." (-0.69)*

The researcher's evaluation in this area is that the students are being taken out of their comfort zone and are required to change learning interventions in order to survive. These students were identifiable and it was noted that their average class grade was $\mathrm{B}+$. They were learning the material, but they did not like the process.

The two statements above (*) had an interesting and strong correlation (0.85). Many students liked this class format and found that it provided a deeper level of learning.

At the end of this survey, the students were provided a section to give their observations and comments. These comments further confirmed that this class format was providing much of its intended goals:

"I really like this class format since I learn better through experience and example. The homework is usually enough to learn/understand the material without being busy work."

"Since in this class we are actually doing everything we are learning, I think that we will understand and remember it better. I have found that I 
generally have some trouble with the concept the first day or two, but after the class reviews have a very good understanding of it."

"Class runs well and teaches fairly well (although the complexity of the material sometimes makes this confusing)."

"Sometimes it is difficult to do homework when we have not covered the topic before. Not always, but sometimes the book is not very clear."

"I really like this class. I am a little bit slow when the teacher asks questions, but it makes me think and put an effort on it."

Our institution utilizes the Individual Development \& Education Assessment (IDEA) as our standard evaluation for all classes. ${ }^{6}$ This tool allows the professor to choose important and essential course objectives from a list that is then evaluated against student responses on a fivepoint scale. For this course the following objectives were chosen:

- Gaining factual knowledge (terminology, classifications, methods, trends)

- Learning fundamental principles, generalizations or theories

- Learning to apply course material (to improve thinking, problem solving, and decisions)

- Developing specific skills, competencies, and points of view needed by professionals in the field most closely related to this course

- Learning to analyze and critically evaluate ideas, arguments, and points of view

- Acquiring an interest in learning more by asking my own questions and seeking answers

The raw scores for these areas ranged from 4.3 to 4.8. When compared against IDEA data in the same discipline (engineering), all objectives were rated as "much higher." This indicates that attaining the objectives was achieved in the highest $10 \%$ of all comparable classes in the national database. This is the highest level of performance as rated by this instrument and was definitely considered to reinforce the course design.

\section{Conclusion}

Although inverted or flip classrooms have often been presented when connected with Web tools for lecture outside of the class, we adapted this concept and coupled it with life-long learning for course design. The results of implementation and the data gathered provides both areas of recommendation and caution:

- Frustration levels may be higher for some of the students as they are pushed to perform in a new environment. But the assessments indicate that learning is enhanced, classroom time is opened to additional application and real-life situations, and students are gaining learning skills that should carry throughout their career. 
- The success of this process is encouraging other faculty to adopt this teaching process. This was initially placed into the first course of a three course sequence; Electrical Systems I. It is now being implemented into the two courses that follow in the sequence.

- We are finding that the students progress faster through the material. The professor does not have to lecture and read the book or reference material to the students. The students are coming to class with a higher level of preparedness. Time is being freed up in the course such that subjects can be taken to a new depth of understanding and additional materials can be placed in the course without sacrificing the quality of existing materials.

- We are cautious in using this methodology for all subjects. As complexity increases for various topics, it is important to make sure that the reading materials thoroughly and clearly presents the information. If the material that is used outside of class is not clear and thorough in its presentation, the instructor will probably have to insert some mini-lectures into the process to establish a proper foundation. It is also recommended that review problems, examples and case studies be provided for the more complex topics as the course proceeds to new information.

At this point, this process is in its third year of usage in the test classrooms. The results have been very encouraging, but matriculation into the workplace is only beginning. Therefore, it will take additional time and research to evaluate the final impact to career, life-long learning.

\section{References}

1 Lage, M.J., Platt, G.J. and Treglia, M.; "Inverting the Classroom: A Gateway to Creating an Inclusive Learning Environment," Journal of Economic Education, Winter 2000; http://www.indiana.edu/ econed/pdffiles/winter00/platt.pdf

2 ABET, Criteria for Accrediting Engineering Programs, 2005-2006, http://www.abet.org/Linked\%20DocumentsUPDATE/Criteria\%20and\%20PP/05-06-EAC\%20Criteria.pdf

3 Bland, L.N. "The Role of Education in the Successful Transition from Technologist to General Manager", Dissertation The Ohio State University, 1996.

4 Baker, J.W.; "The "Classroom Flip": Using Web Course Management Tools to Become the Guide by the Side," Selected Papers from the $11^{\text {th }}$ International Conference on College Teaching and Learning, J.A. Chambers, editor, Center for Advancement of Teaching and Learning, Jacksonville, FL, 2000.

5 Fink, L.D.; Creating Significant Learning Experiences, Jossey-Bass, San Francisco, CA, 2003.

6 Individual Development \& Education Assessment (IDEA), http://www.idea.ksu.edu/ 